\title{
Adaptação de um wiki para a informatização da documentação do Sistema de Gestão da Qualidade
}

\section{Adaptation of a wiki to computerize Quality Management System documentation}

\author{
Graziele Cristina Silveira Zerbini Costal ${ }^{1}$ \\ João Batista Turrioni ${ }^{2}$ \\ Roberto Antonio Martins ${ }^{1}$
}

\begin{abstract}
Resumo: A documentação de um Sistema de Gestão da Qualidade padrão ISO 9001 é muitas vezes vista como uma fonte de burocracia nas organizações. Este artigo descreve o WikiQMS como uma alternativa para a informatização da documentação de tal sistema. O método científico foi aplicado para o desenvolvimento do sistema. O protótipo foi desenvolvido a partir de um software wiki, com base nos requisitos da ISO 9001 levantados na literatura e também pela avaliação de um painel de especialistas. O experimento de campo em uma empresa júnior permitiu validar o sistema em uma situação real de implantação da documentação do Sistema de Gestão da Qualidade. O protótipo atende adequadamente aos requisitos mínimos de implantação e gestão da documentação do Sistema de Gestão da Qualidade padrão ISO 9001. Além disso, o WikiQMS apresenta as vantagens de uma solução da Web 2.0 para a questão da edição colaborativa, autoria coletiva, acessibilidade e usabilidade.
\end{abstract}

Palavras-chave: Sistema de Gestão da Qualidade. ISO 9001. Wiki. Web 2.0. Documentação.

\begin{abstract}
The ISO 9001 compliant Quality Management System documentation often creates bureaucracy in organizations. This paper describes the WikiQMS as an alternative for computerizing the documentation of this system. The scientific method was applied to develop the system. The prototype was developed using the Wiki software based on the ISO 9001 requirements found in the literature review and on an Expert Panel evaluation. The field experiment in a junior enterprise enabled to validate the system in a real setting of implementation of Quality Management System documentation. The prototype complies with the minimum requirements for implementation and management of ISO 9001 Quality Management System. Furthermore, The WikiQMS offers some advantages of Web 2.0 such as collaborative editing, collective authorship, accessibility, and usability.
\end{abstract}

Keywords: Quality Management System. ISO 9001. Wiki. Web 2.0. Documentation.

\section{Introdução}

A ISO 9001 tem sido amplamente utilizada como modelo para o projeto, implantação e manutenção de Sistemas de Gestão da Qualidade (SGQs) no Brasil e no mundo. A Figura 1 apresenta a evolução de certificados ISO 9001 emitidos para empresas que operam no país. No geral, observa-se que ao longo de 19 anos houve uma evolução considerável - de 113 certificados, em 1993, para 25.791, em 2012. Todavia, o pico foi em 2011, quando foram 28.325 certificados. O número de certificados em 2012 é menor que nos dois anos anteriores, mas é considerável o salto entre 2009 e 2010.

Apesar do crescimento ilustrado na Figura 1, muitas críticas são feitas em relação à norma e ao processo de certificação. Stevenson e Barnes (2001) citam como críticas o alto custo do processo de certificação, a diferença nas interpretações dos auditores, o não atendimento às necessidades de indústrias específicas e o excesso de documentos e de burocracia. Por sua vez, a International Organization for Standardization (ISO) tem se esforçado para lidar com esses problemas na atualização e publicação de novas versões da norma. Tal esforço em relação à documentação pode ser visto na publicação da versão de 2000 da ISO 9001. Nessa versão, a documentação exigida foi simplificada e o foco passou a ser na determinação e implantação dos processos de gestão da qualidade, ao invés de na documentação.

\footnotetext{
${ }^{1}$ Departamento de Engenharia de Produção - DEP, Universidade Federal de São Carlos - UFSCar, Rod Washington Luís, km 235, CEP 13565-905, São Carlos, SP, Brasil, e-mail: gcosilveira@yahoo.com.br; ram@dep.ufscar.br

2 Instituto de Engenharia de Produção e Gestão - IEPG, Universidade Federal de Itajubá - UNIFEI, Av. BPS, 1303, CEP 37500-903, Itajubá, MG, Brasil, e-mail: joabatu@gmail.com
} 


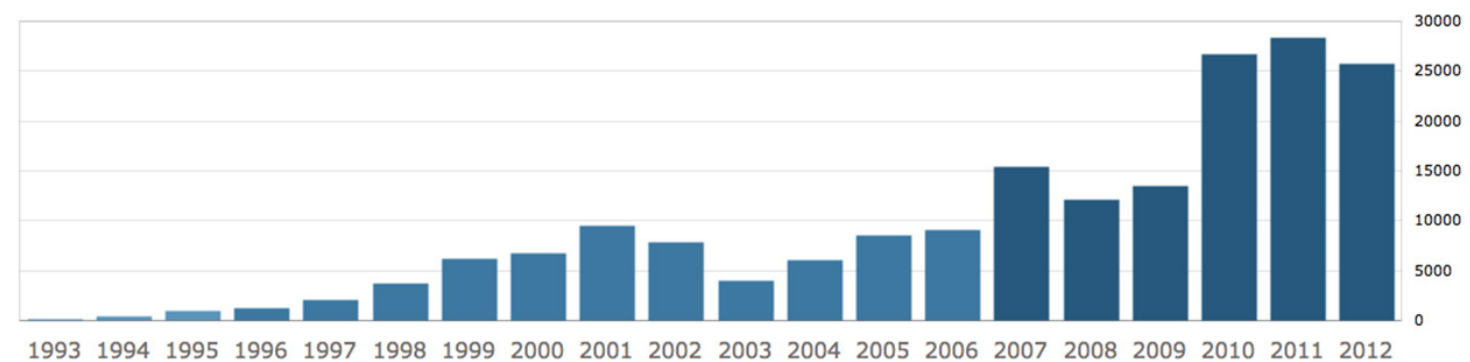

Figura 1. Evolução de certificados ISO 9001 no Brasil. Fonte: ISO (INTERNATIONAL..., 2013).

Apesar da mudança positiva com a nova versão da ISO 9001, a documentação e sua gestão ainda continuam uma das principais dificuldades encontradas pelas organizações (POKSINSKA; EKLUND; DAHLGAARD, 2006; PINTO; CARVALHO; HO, 2006; ANHOLON; ZOQUI; PINTO, 2005; ANTUNES; RIBEIRO, 2005; SLONGO et al., 2005). Essa dificuldade passa a impressão de que o SGQ tem a função de manter e atualizar documentos e não de gerir e melhorar processos (POKSINSKA; EKLUND; DAHLGAARD, 2006).

Para lidar com a complexidade da gestão da documentação, segundo os requisitos da norma ISO 9001, a informatização é normalmente uma solução empregada. A documentação e as atividades de manutenção, atualização e publicação, antes realizadas com a manipulação de papéis, podem ser facilmente geridas pelos sistemas informatizados. Newman e Thomas (2009) ainda destacam que os softwares utilizados para essa função têm evoluído, passando de softwares de desktop para baseados em web. A própria web evoluiu, com o fenômeno de surgimento de softwares e tecnologias conhecido como Web 2.0.

A Web 2.0 possui vários softwares que apresentam como características o desenvolvimento de conteúdo de forma colaborativa, o uso da internet para compartilhamento, o enriquecimento do conteúdo e a facilidade na criação e busca de conteúdos (McAFEE, 2009; NEWMAN; THOMAS, 2009; BEST, 2006; TREDINNICK, 2006; O'REILLY, 2005).

Na gestão da documentação, um software da Web 2.0 de grande potencial é o wiki. $\mathrm{O}$ wiki possui diversos mecanismos que favorecem a melhoria contínua dos documentos, como a facilidade de acesso e edição, o uso de hiperlinks e o controle de autoria e histórico (ELSMAR..., 2009).

Atualmente, os softwares encontrados no mercado ou desenvolvidos internamente pelas organizações não utilizam o potencial da Web 2.0. Além disso, os softwares proprietários normalmente apresentam alto custo de aquisição e, segundo Nilles (2001), requerem customizações adicionais que resultam em um encarecimento significativo do orçamento inicial.
Já em relação ao wiki, a maioria dos softwares wiki existentes é de custo zero de aquisição e também de código aberto, podendo ser customizados de acordo com as necessidades da organização.

O objetivo do presente artigo é descrever o WikiQMS (Wiki Quality Management System), um sistema adaptado de um software wiki para a informatização da documentação de um Sistema de Gestão da Qualidade padrão ISO 9001. Esse sistema é resultado de customizações e mudanças no código do software Tiki Wiki CMS Groupware que permitiram a implantação de um workflow de aprovação de documentos, de grupos de usuários com permissões distintas dentro do workflow, de meios de comunicação automáticos e não automáticos entre os usuários, autores e aprovadores do SGQ, de modelos de documentos com seções padronizadas e de telas com seções customizadas para facilitar o acesso e diferenciação do estado dos documentos.

Este artigo está organizado da seguinte forma: a seção 2 apresenta a fundamentação teórica sobre o Sistema de Gestão da Qualidade, o software wiki dentro do fenômeno da Web 2.0, a informatização do SGQ e os requisitos para informatização do SGQ; a seção 3 descreve o experimento de campo, abrangendo as etapas de desenvolvimento e o funcionamento do WikiQMS; e, por fim, a seção 4 traz as considerações finais do artigo e as perspectivas para trabalhos futuros.

\section{Fundamentação teórica}

A fundamentação teórica está dividida em quatro partes. Primeiramente, aborda-se a teoria sobre o Sistema de Gestão da Qualidade e a norma ISO 9001. A segunda parte apresenta a revisão sobre o software wiki dentro do fenômeno da Web 2.0. Na terceira seção, é discutida a informatização da documentação. Por fim, a última seção aborda os requisitos levantados a partir da fundamentação teórica e que apoiaram as demais etapas da pesquisa.

\subsection{Sistema de Gestão da Qualidade}

O Sistema de Gestão da Qualidade consiste no componente do sistema de gestão da empresa que visa 
atingir os objetivos da qualidade, de forma a atender os requisitos e necessidades dos clientes e outras partes interessadas (ASSOCIAÇÃO..., 2005). A norma ISO 9001 tem por objetivo apresentar requisitos para um SGQ que enfatizam a eficácia do SGQ em atender aos requisitos dos clientes. O certificado nessa norma é normalmente exigido por clientes para que eles possam realizar compras nas organizações. No entanto, mesmo sem exigência, a aplicação dos requisitos da ISO 9001 pode resultar em benefícios internos para as organizações (CARPINETTI; MIGUEL; GEROLAMO, 2010; MELLO et al., 2009).

Os requisitos da norma ISO 9001 são divididos em oito seções: escopo, referência normativa, termos e definições, Sistema de Gestão da Qualidade, responsabilidade da direção, gestão de recursos, realização do produto e medição, análise e melhoria. Silva (2006) caracteriza as três primeiras seções como referenciais e as cinco restantes como específicas.

As seções referenciais introduzem o objetivo da norma e seus principais aspectos, além de tratarem de sua aplicação nas organizações. Já as cinco seções restantes, segundo Carpinetti, Miguel e Gerolamo (2010), podem ser visualizadas como processos de gestão da qualidade interligados.

Na quarta seção da norma, denominada Sistema de Gestão da Qualidade, abordam-se requisitos gerais do SGQ e os requisitos para sua documentação, que embasam e afetam todos os demais requisitos. Os requisitos de documentação, em particular, tratam dos tipos de documentos necessários e de como deve ser feito o seu controle. A norma ISO 9001 estabelece como tipos de documentos necessários as declarações da política e dos objetivos da qualidade, o manual da qualidade, os procedimentos requeridos pela norma e os documentos e registros necessários para assegurar planejamento, operação e controle eficazes dos processos (ASSOCIAÇÃO..., 2008).

A norma ISO 9001 reserva dois requisitos ao controle de documentos, sendo que um trata especificamente do controle de registros. De uma forma geral, os requisitos de controle de documentos tratam de assegurar a disponibilidade do documento quando e onde ele é necessário, de controlar o acesso a esses documentos e também do processo de análise crítica desses documentos (ASSOCIAÇÃO..., 2008).

No que diz respeito à disponibilidade dos documentos da qualidade, a norma ISO 9001 requer que as versões pertinentes estejam disponíveis nos locais de uso. Segundo Hoyle (2009), a disponibilidade não representa a necessidade de os usuários possuírem cópias dos documentos, mas sim a de garantir o acesso aos documentos. A legibilidade e capacidade de identificação também devem ser observadas. Essa identificação deve se estender às alterações e situação da revisão atual dos documentos.
Quanto ao controle no acesso, a norma ISO 9001 exige que os documentos disponibilizados tenham sido aprovados previamente, controlando o acesso aos rascunhos gerados para a criação do documento final. Além disso é necessário impedir o uso não intencional de documentos obsoletos. O controle dos documentos deve se estender aos documentos externos (ASSOCIAÇÃO..., 2008).

A análise crítica consiste em outro aspecto abordado pela norma sobre o controle de documentos. Aplicando-se de forma periódica ou randômica, segundo Hoyle (2009), o processo de análise crítica envolve definir a necessidade de atualização ou não do documento. Se o documento é atualizado, é necessária uma nova aprovação para publicação do documento.

Os registros possuem forma de controle diferente por possuírem a função específica de fornecerem evidências da aplicação dos documentos normativos (HOYLE, 2009; CARPINETTI; MIGUEL; GEROLAMO, 2010). Esses controles envolvem critérios para identificação, armazenamento, proteção, recuperação, retenção e disposição dos registros.

Costal e Martins (2011) mencionam que a dificuldade com os requisitos da documentação da ISO 9001 é uma das mais citadas em surveys e estudos de casos que abordam os obstáculos na adoção da norma. Outras dificuldades citadas consistem nos altos custos de manutenção da certificação, a falta de envolvimento de colaboradores e alta direção, a mudança cultural e a falta de tempo e outros recursos para lidar com a gestão da qualidade. Pode-se notar que essas dificuldades também se relacionam com a documentação.

Os motivos para as dificuldades na gestão da documentação envolvem a criação de documentos mais burocráticos que o necessário, a documentação excessiva, o controle da documentação e o preenchimento de registros (COSTAL, 2012).

\subsection{Wiki}

O termo Web 2.0 é muitas vezes utilizado para definir o movimento de surgimento de softwares, tecnologias e ideias que surgiram a partir de 1997 na web. As principais características dos softwares e serviços dessa nova web abrangem o uso de plataformas em vez de canais de comunicação, a competência central da gestão de banco de dados, a atualização contínua, o provimento de uma experiência rica do usuário, a escalabilidade, a modularidade, a possibilidade de combinação de informações, o hipertexto e o sistema de alertas para atualização de conteúdo (HALL, 2011; McAFEE, 2009; BEST, 2006; MILLER, 2005; O'REILLY, 2005).

Dentro desse movimento, podem-se destacar como softwares e tecnologias características os sites de mídias e redes sociais, os blogs, os softwares Rich 
Internet Applications (RIA), o tagging, os sites de bookmarking, Software as a Service (SaaS), os mecanismos de avisos como o Real Simple Syndication (RSS) e Atom, os softwares mashups e wikis (NEWMAN; THOMAS, 2009). Essas tecnologias podem ser usadas em diferentes contextos, como no uso pessoal, por comunidades, pelo governo e por empresas.

Na questão da gestão da documentação, o wiki é uma tecnologia de grande potencial e também é considerada a tecnologia que melhor simboliza as características da Web 2.0. O wiki pode ser definido como um software on-line que objetiva a criação colaborativa e coletiva de conteúdos em formato de páginas web.

O primeiro wiki surgiu em 1995, quando Ward Cunningham criou o conceito de servidor WikiWikiWeb para publicar padrões de software de forma colaborativa na web. A abordagem utilizada por Ward foi criar a base de dados on-line funcional mais simples possível, sendo que o software foi liberado na web para que todos pudessem utilizá-lo (EBERSBACH et al., 2008; LEUF; CUNNINGHAM, 2001). A partir desse primeiro wiki, vários outros foram criados com funcionalidades derivadas das ideias originais incorporadas no WikiWikiWeb, sendo chamados de clones de wiki. Apesar de diversas evoluções ocorridas, as características centrais do software wiki estão no Quadro 1.

\subsection{Informatização do Sistema de Gestão da Qualidade}

A gestão de documentos do SGQ deve levar em consideração o controle do fluxo informacional (classificação e indexação) e a avaliação dos documentos produzidos e recebidos (CARDOSO; LUZ, 2004). As tecnologias de armazenamento de informações evoluíram bastante nos últimos tempos (SPRAGUE, 1995). Atualmente, os softwares podem lidar com diferentes graus de independência em relação à documentação em papel com destaque para o processamento de documentos digitais (ou eletrônicos). Neles, as informações podem ser armazenadas não só em formato textual, mas também por meio de símbolos gráficos, imagens, fotos, áudio, vídeo e animações. Nos últimos anos, ganharam destaque os documentos $100 \%$ digitais, ou seja, que são armazenados e validados eletronicamente (VASQUES, 2007).

Em uma pesquisa do Forrester Research Inc. com 41 executivos de TI que utilizaram 68 pacotes de softwares de qualidade, descobriu-se que, apesar

Quadro 1. Características do software wiki.

\begin{tabular}{|c|c|}
\hline Tipo & Característica \\
\hline \multirow{5}{*}{ Características principais } & Armazenamento das páginas wiki em um repositório central e compartilhado; \\
\hline & Controle, armazenamento e recuperação de versões; \\
\hline & $\begin{array}{l}\text { Edição fácil e acessível, sem necessidade de ferramentas especiais ou softwares } \\
\text { proprietários. Só necessitam do navegador; }\end{array}$ \\
\hline & Formatação das informações nas páginas wiki mais fácil que a linguagem HTML; \\
\hline & Estrutura de hipertexto não linear navegável por links entre páginas. \\
\hline \multirow{8}{*}{$\begin{array}{l}\text { Características } \\
\text { complementares }\end{array}$} & Disponibilidade de uma lista de páginas recentemente modificadas; \\
\hline & Anexação de arquivos às páginas wiki; \\
\hline & Navegação por páginas que se conectam à cada página aberta (backlinks); \\
\hline & Notificação por $e$-mail quando uma página é modificada; \\
\hline & Mecanismo de busca; \\
\hline & Páginas imprimíveis; \\
\hline & Facilidade de customização; \\
\hline & Taxonomia (tags) e outras formas de classificação. \\
\hline \multirow{3}{*}{ Wikis estruturados } & Variáveis; \\
\hline & Modelos de documentos; \\
\hline & Formulários. \\
\hline \multirow{2}{*}{ Wikis corporativos } & Controle de acesso; \\
\hline & Controle de permissões. \\
\hline \multirow{3}{*}{$\begin{array}{l}\text { Funcionalidades normais de } \\
\text { um software }\end{array}$} & Backup; \\
\hline & Capacidade de inserção de comentários; \\
\hline & Mecanismos de integração (RSS, web services, conexão com outros sites etc.) \\
\hline
\end{tabular}

Fonte: adaptado de Costal (2012, p. 79). 
de $95 \%$ das empresas comprarem os softwares sem intenção de customizá-los, menos de $10 \%$ dos programas foram implantados sem customização. Esse cenário é agravado pelo fato de que customizações são geralmente caras ( $10 \%$ de customização adicional representam aumento de $20 \%$ no valor original da customização por ano). Apesar desse cenário preocupante, isso não significa que a melhor opção dos gerentes da qualidade é voltar para o SGQ em papel, mas sim buscar um software que dê flexibilidade, que permita configurar e alterar a configuração dos softwares pré-existentes sem programação (autocustomização) e que ofereça notificações por e-mail automáticas. É recomendado o uso de programas que trabalhem com navegadores de web, ou seja, de softwares baseados em web. Esse tipo de software apresenta grandes vantagens de custo para empresas de todos os tamanhos, pois as despesas envolvidas já foram realizadas (instalação do navegador nos computadores), não são requeridas licenças múltiplas e há menores custos de treinamento, pois a familiaridade dos usuários com softwares web torna o treinamento mais rápido (NILLES, 2001).

Além do alto custo, os softwares atualmente disponíveis para aquisição e os desenvolvidos internamente geralmente não utilizam o potencial das tecnologias da Web 2.0, dentre elas o do wiki. O uso de wiki para informatização do SGQ consiste em uma proposta e realidade nova para esse tema. Costal e Martins (2010) argumentam que as principais vantagens para a aplicação do wiki consistem no armazenamento de seus arquivos em um repositório central e compartilhado, usabilidade, enriquecimento do conteúdo, uso de hipertexto, controle de versões e histórico, mecanismo de busca nos títulos, palavras-chave e conteúdo dos documentos, notificações por $e$-mail e lista das últimas mudanças realizadas.

A literatura pesquisada sobre a utilização de wikis para a informatização da documentação do Sistema de Gestão da Qualidade é escassa. O Quadro 2 apresenta um sumário dos usos encontrados na pesquisa bibliográfica realizada.

Pode-se observar que os usos descritos em Castaño, Mendez e Day (2012) e García et al. (2010) têm o maior escopo e, especificamente, García et al. (2010) utilizam mais plug-ins. Esses mesmos autores utilizam a versão do MediaWiki para web semântica. As propostas que utilizam o Wikimedia, software utilizado na enciclopédia Wikipedia, são os que mais necessitam de plug-ins para suprir a falta de funcionalidade do software. Todas as aplicações foram para situações específicas de empresas que contam com recursos humanos qualificados. Talvez a exceção seja a Geometrica, que utilizou o software Bugzilla para capturar informação de usuários resistentes ao wiki. Todavia, isso não fica claro em Castaño, Mendez e Day (2012).

Quadro 2. Resumos dos usos de wiki em Sistema de Gestão da Qualidade.

\begin{tabular}{|c|c|c|c|c|}
\hline Referência & Escopo & Implantação & $\begin{array}{c}\text { Wiki } \\
\text { utilizado }\end{array}$ & $\begin{array}{c}\text { Outros softwares ou } \\
\text { plug-ins }\end{array}$ \\
\hline $\begin{array}{l}\text { Castaño, Mendez e } \\
\text { Day (2012) }\end{array}$ & $\begin{array}{l}\text { Política e objetivos da } \\
\text { qualidade } \\
\text { Gestão da documentação } \\
\text { Gestão dos processos } \\
\text { Auditoria interna } \\
\text { Melhoria contínua }\end{array}$ & $\begin{array}{l}\text { Geometrica - empresa } \\
\text { de projetos e instalação } \\
\text { de estruturas }\end{array}$ & Project Forum & $\begin{array}{l}\text { Bugzilla para informar } \\
\text { não conformidades e } \\
\text { propor melhorias }\end{array}$ \\
\hline García et al. (2010) & $\begin{array}{l}\text { Política e objetivos da } \\
\text { qualidade } \\
\text { Gestão da documentação } \\
\text { Gestão dos processos } \\
\text { Auditoria interna } \\
\text { Melhoria contínua }\end{array}$ & $\begin{array}{l}\text { Grupo de pesquisa } \\
\text { GRIHO }\end{array}$ & $\begin{array}{c}\text { Semantic } \\
\text { MediaWiki }\end{array}$ & $\begin{array}{l}\text { Semantic forms } \\
\text { Loop functions } \\
\text { Parser functions } \\
\text { Timelines } \\
\text { PermissionACL }\end{array}$ \\
\hline Gomide (2009) & Gestão da documentação & $\begin{array}{l}\text { Grupo PET da } \\
\text { Engenharia de } \\
\text { Produção da UFSC }\end{array}$ & Wikimedia & $\begin{array}{l}\text { FlaggedRevs para } \\
\text { aprovação e publicação } \\
\text { (workflow) } \\
\text { FCKEditor para } \\
\text { editoração de } \\
\text { documentos }\end{array}$ \\
\hline Lavrsen (2007) & $\begin{array}{l}\text { Gestão da documentação } \\
\text { Gestão dos erros de código } \\
\text { Rastreabilidade }\end{array}$ & $\begin{array}{l}\text { Centro Copenhagen } \\
\text { Motorola Tetra } \\
\text { World Wide System } \\
\text { Development }\end{array}$ & Twiki & $\begin{array}{l}\text { ClearQuest da IBM }{ }^{\circledR} \\
\text { que gerir erros de } \\
\text { código }\end{array}$ \\
\hline
\end{tabular}




\subsection{Requisitos de documentação de um Sistema de Gestão da Qualidade ISO 9001}

Como um dos resultados da fundamentação teórica, foram estabelecidos os requisitos do software para informatização da documentação de um SGQ ISO 9001. Eles foram levantados a partir da revisão da literatura sobre os requisitos da norma ISO 9001 (ASSOCIAÇÃO..., 2008), recomendações de autores sobre a implantação e manutenção de um SGQ (CARPINETTI; MIGUEL; GEROLAMO, 2010; CIANFRANI; TSIAKALS; WEST, 2009; HOYLE, 2009; MELLO et al., 2009; CAMPOS, 1992, 2004; FEIGENBAUM, 1994) e sobre as dificuldades encontradas nas organizações nesse quesito (COSTAL; MARTINS, 2011; SAMPAIO; SARAIVA; RODRIGUES, 2009; DEPEXE; PALADINI, 2007; ANHOLON; ZOQUI; PINTO, 2005; ANTUNES; RIBEIRO, 2005; SLONGO et al., 2005; CASADESÚS; HERAS; ARANA, 2004; DOUGLAS; COLEMAN; ODDY, 2003; STEVENSON; BARNES, 2001). Os requisitos são apresentados nos Quadros 3 e 4.

\section{Experimento de campo}

De acordo com a abordagem multimetodológica para sistemas de informações de Nunamaker Junior,
Chen e Purdin (1990), a estratégia de pesquisa desenvolvimento de sistemas é considerada como método central. $\mathrm{O}$ artefato resultante serve como ponte entre a pesquisa tecnológica (conceito) e a pesquisa social (impacto). Além disso, para formar um programa de pesquisa dinâmico e integrado, o desenvolvimento de sistemas deve interagir com outras três estratégias de pesquisa: a construção teórica (estrutura conceitual, modelos matemáticos e métodos), a observação (estudos de caso, surveys e estudos de campo) e a experimentação (simulações computacionais, experimentos de laboratório e experimentos de campo).

Nunamaker Junior, Chen e Purdin (1990) sugerem como etapas para a pesquisa de desenvolvimento de sistemas a construção da estrutura conceitual, o desenvolvimento da arquitetura do sistema, a análise e projeto do sistema, a construção do protótipo e a sua observação e avaliação. A Figura 2 ilustra o processo para a pesquisa de desenvolvimento de sistemas.

Para o desenvolvimento do WikiQMS, o experimento de campo foi escolhido como método de pesquisa. A escolha foi feita devido à importância do teste do protótipo em uma situação real. Galliers e Land (1987) sublinham essa importância ao alegar que o sucesso de uma pesquisa em uma área aplicada como a de sistemas de informações se mede pela capacidade

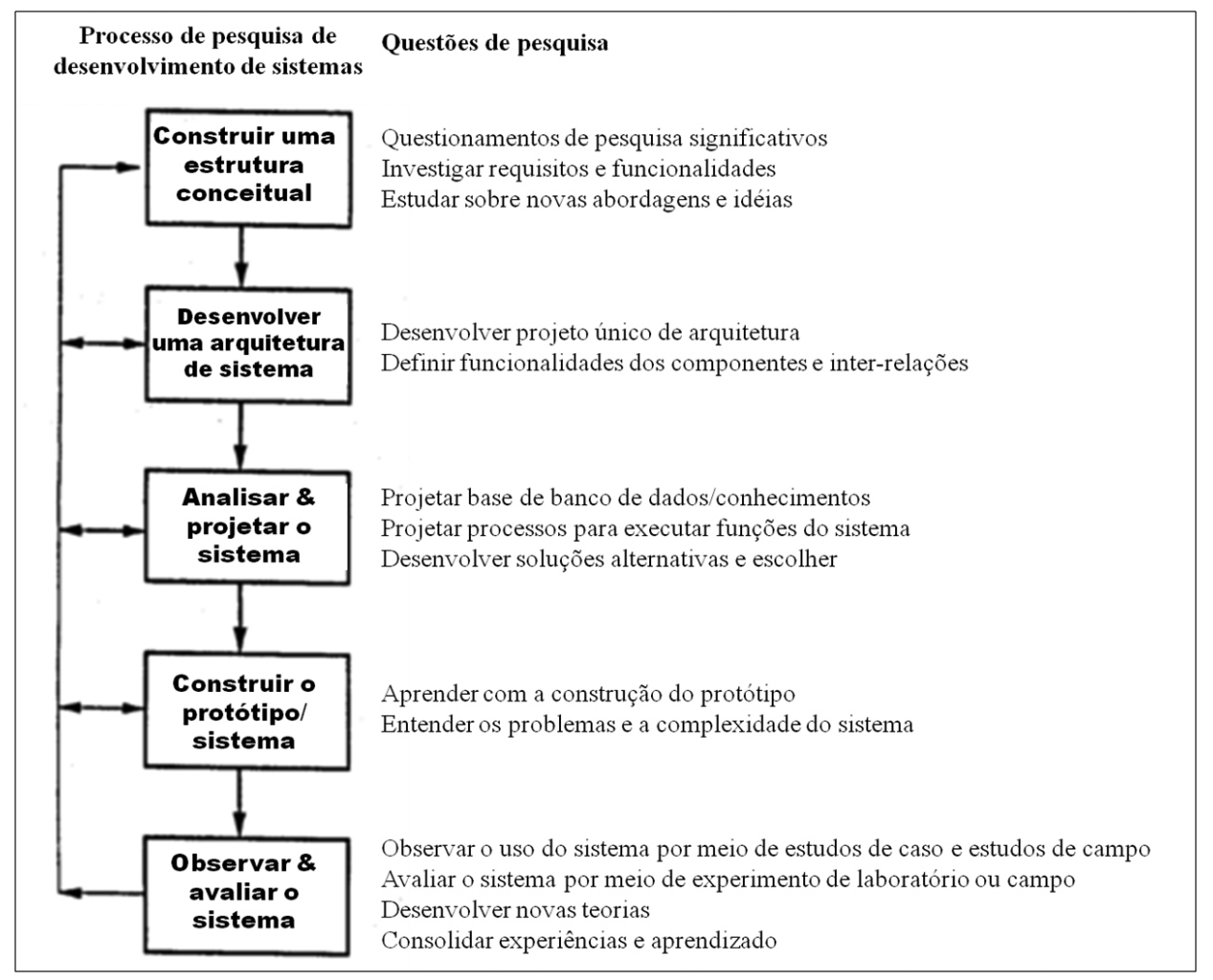

Figura 2. Processo para a pesquisa de desenvolvimento de sistemas. Fonte: Adaptado de Nunamaker Junior, Chen e Purdin (1990). 
Quadro 3. Requisitos funcionais do software para informatização de um SGQ ISO 9001.

\begin{tabular}{|c|c|c|}
\hline Função principal & Cód. & Requisito \\
\hline \multirow{6}{*}{$\begin{array}{l}\text { Armazenamento } \\
\text { de documentos }\end{array}$} & 1 & $\begin{array}{l}\text { Armazenamento e leitura de documentos predominantemente em forma de texto } \\
\text { (documentos normativos); }\end{array}$ \\
\hline & 2 & $\begin{array}{l}\text { Armazenamento e leitura de documentos sob a forma de formulários (documentos } \\
\text { comprobatórios); }\end{array}$ \\
\hline & 3 & Armazenamento de documentos externos; \\
\hline & 4 & Legibilidade dos documentos normativos; \\
\hline & 5 & Manutenção dos registros em boas condições; \\
\hline & 6 & Proteção dos registros e documentos normativos. \\
\hline \multirow{6}{*}{$\begin{array}{l}\text { Manipulação de } \\
\text { documentos }\end{array}$} & 7 & Criação e modificação de documentos normativos; \\
\hline & 8 & Criação e modificação de documentos comprobatórios; \\
\hline & 9 & Capacidade de remoção de registros (disposição); \\
\hline & 10 & Capacidade de anexar arquivos aos documentos normativos e comprobatórios; \\
\hline & 11 & $\begin{array}{l}\text { Capacidade de referenciar outros documentos ou capacidade de inclusão de documentos } \\
\text { dentro de documentos normativos; }\end{array}$ \\
\hline & 12 & Impressão \\
\hline \multirow{11}{*}{$\begin{array}{l}\text { Recuperação de } \\
\text { documentos }\end{array}$} & 13 & Identificação dos documentos normativos (exemplos: classificação, título); \\
\hline & 14 & Recuperação de todos os registros; \\
\hline & 15 & Registros devem ser prontamente identificáveis; \\
\hline & 16 & Sistema de busca de dados e informações; \\
\hline & 17 & Mecanismo de controle de versões dos documentos normativos; \\
\hline & 18 & Disponibilidade do histórico das versões dos documentos normativos; \\
\hline & 19 & Identificação das alterações efetuadas nos documentos normativos; \\
\hline & 20 & Disponibilidade da versão pertinente dos documentos nos locais de uso; \\
\hline & 21 & Se necessário, permissão para acesso fora do horário normal de trabalho; \\
\hline & 22 & Visualização da versão mais atualizada dos dados dos registros; \\
\hline & 23 & $\begin{array}{l}\text { Preservação das informações originais no caso de alterações nas informações dos } \\
\text { registros. }\end{array}$ \\
\hline \multirow{9}{*}{$\begin{array}{l}\text { Controle de } \\
\text { permissões }\end{array}$} & 24 & $\begin{array}{l}\text { Capacidade de impedir mudanças e remoção indevidas em versões eletrônicas de } \\
\text { documentos externos; }\end{array}$ \\
\hline & 25 & Capacidade de impedir a remoção inadvertida dos documentos comprobatórios; \\
\hline & 26 & $\begin{array}{l}\text { Mecanismo que obriga necessidade de autorização se há necessidade de mudança das } \\
\text { informações de registro que já foi completamente preenchido; }\end{array}$ \\
\hline & 27 & $\begin{array}{l}\text { Mecanismo de controle de permissões (acesso, alteração, aprovação) por grupo de } \\
\text { usuários para todos os tipos de documentos normativos e comprobatórios; }\end{array}$ \\
\hline & 28 & Mecanismo de controle da autorização para recuperação de registros; \\
\hline & 29 & Capacidade de impedir alteração não autorizada do documento normativo ou comprobatório; \\
\hline & 30 & Possibilidade de acesso a documentos de versões anteriores a algumas pessoas; \\
\hline & 31 & $\begin{array}{l}\text { Capacidade de impedir acesso a versões inválidas dos documentos normativos e } \\
\text { comprobatórios aos usuários que não podem visualizá-las; }\end{array}$ \\
\hline & 32 & Capacidade de impedir acesso a documentos obsoletos. \\
\hline \multirow{7}{*}{ Controle de status } & 33 & Visualização de quando o registro foi removido; \\
\hline & 34 & Mecanismo de identificação de autoria na elaboração e alteração dos documentos normativos; \\
\hline & 35 & Identificação da situação da revisão atual; \\
\hline & 36 & $\begin{array}{l}\text { Padronização na identificação de versões de documentos normativos e comprobatórios } \\
\text { (diferenciada para documentos finais e rascunhos); }\end{array}$ \\
\hline & 37 & Capacidade de estabelecer o status do sistema de documentação normativa a qualquer momento; \\
\hline & 38 & Identificação dos documentos normativos obsoletos; \\
\hline & 39 & Monitoramento de mudanças nas informações dos documentos normativos. \\
\hline \multirow{2}{*}{ Workflow } & 40 & $\begin{array}{l}\text { Mecanismo de aprovação de documentos cujo conteúdo foi alterado ou criado antes da } \\
\text { publicação no caso de documentos normativos; }\end{array}$ \\
\hline & 41 & $\begin{array}{l}\text { Mecanismo que garanta que documentos normativos publicados no domínio dos usuários } \\
\text { já foram aprovados e que proiba os demais documentos de serem publicados. }\end{array}$ \\
\hline
\end{tabular}

Fonte: Autores. 
Quadro 4. Requisitos não funcionais do software para informatização de um SGQ ISO 9001.

\begin{tabular}{|c|c|l|}
\hline Função principal & Cód. & \multicolumn{1}{|c|}{ Requisito } \\
\hline \multirow{4}{*}{ Manutenabilidade } & 42 & $\begin{array}{l}\text { As linguagens utilizadas pelos softwares devem ser conhecidas pela equipe que vai } \\
\text { customizar o sistema; }\end{array}$ \\
\cline { 2 - 3 } & 43 & Disponibilidade de manual de suporte à implantação adequado; \\
\cline { 2 - 3 } & 44 & Disponibilidade de fóruns e outras ferramentas de suporte adequadas; \\
\cline { 2 - 3 } & 45 & Código livre; \\
\cline { 2 - 3 } & 46 & Sistema já bem desenvolvido, com poucos bugs. \\
\hline Custos & 47 & Gratuidade na obtenção. \\
\hline Segurança & 48 & Backup fácil e completo. \\
\hline \multirow{2}{*}{ Usabilidade } & 49 & Interface intuitiva para administração e utilização; \\
\cline { 2 - 4 } & 50 & Edição fácil do conteúdo das páginas. \\
\hline Flexibilidade & 51 & Variedade de plug-ins e complementos. \\
\hline
\end{tabular}

Fonte: Autores.

do conhecimento ter sido melhorada a ponto de ele poder ser aplicado na prática. Nunamaker Junior, Chen e Purdin (1990) também enfatizam a importância da combinação do desenvolvimento do sistema com a pesquisa de campo e afirmam que a transferência de tecnologia representa o sucesso definitivo das teorias, conceitos e sistemas desenvolvidos na pesquisa em sistemas de informação.

\subsection{Etapas de desenvolvimento do protótipo}

O desenvolvimento do WikiQMS foi feito a partir de quatro etapas: (1) construção de um referencial teórico-conceitual; (2) escolha de um software wiki; (3) desenvolvimento da arquitetura e construção do protótipo; e (4) validação com a implantação em uma situação real. Esses passos são adaptados da Figura 2 apresentada anteriormente.

A construção do referencial teórico-conceitual foi feita a partir da revisão bibliográfica sobre os requisitos de documentação de um Sistema de Gestão da Qualidade padrão ISO 9001 e a caracterização da Web 2.0 e do wiki. Ambos permitiram caracterizar o uso do wiki para um Sistema de Gestão da Qualidade padrão ISO 9001. O sítio Wikimatrix (http://www. wikimatrix.org) foi utilizado para identificar e caracterizar os softwares wiki existentes.

Esses dois grupos de informações foram utilizadas para a escolha do software wiki mais adequado para desenvolver o protótipo. A escolha do software foi realizada por meio de uma filtragem progressiva nos softwares wiki disponibilizados pelo serviço de busca customizada do Wikimatrix. A filtragem ocorreu em três rodadas, sendo que a segunda definiu os aplicativos viáveis e a terceira permitiu escolher o wiki a ser utilizado no desenvolvimento do WikiQMS. A escolha foi pelo software Tiki Wiki CMS Groupware. Os detalhes da escolha serão apresentados na próxima seção.

A terceira etapa envolveu o desenvolvimento da arquitetura do sistema e a construção do protótipo.
A etapa de desenvolvimento do protótipo envolveu inicialmente a instalação e configuração do software Tiki Wiki, o planejamento do desenho do protótipo de acordo com os requisitos levantados na etapa de revisão da literatura e sua implantação. A primeira versão do protótipo foi então submetida à avaliação em um painel de especialistas, o que consistiu etapa importante para contemplação da perspectiva de usuários potenciais na definição dos requisitos a serem atendidos pelo protótipo.

O painel consistiu em quatro etapas principais: a seleção dos participantes, a elaboração e envio do questionário, o recebimento dos questionários respondidos e a análise de conteúdo dos resultados. Os participantes do painel foram quatro membros da comunidade acadêmica especialistas na área de sistemas de gestão da qualidade e quatro profissionais de empresas que têm ou já tiveram experiência como gerentes ou coordenadores da gestão da qualidade.

O questionário enviado continha a descrição das funcionalidades centrais do protótipo e perguntas sobre como os participantes avaliavam cada uma das funcionalidades, quais críticas e sugestões apresentavam com relação a elas. Após o recebimento de todos os questionários respondidos, as respostas foram analisadas segundo técnica de análise de conteúdo. A partir da análise das respostas obteve-se uma visão geral de como o protótipo foi avaliado e uma relação de críticas e sugestões para sua melhoria. Algumas das intervenções sugeridas foram incorporadas ao protótipo, gerando sua segunda versão.

Por fim foi feita a validação do protótipo, por meio do experimento de campo com a implantação em uma situação real, na empresa júnior Unifei Jr. A validação foi feita em três ações. Primeiramente foi feita a preparação para a implantação, a instalação e configuração inicial. Em seguida, o WikiQMS foi utilizado por grupo de integrantes da empresa júnior responsáveis pela gestão da qualidade e outros processos. Por fim foi obtido o feedback do grupo que participou da implantação do WikiQMS na Unifei Jr. 


\subsection{WikiQMS}

Esta seção apresenta os principais resultados do processo de pesquisa para desenvolvimento do WikiQMS e do experimento de campo.

\subsubsection{Primeira versão do protótipo}

O WikiQMS foi construído a partir do software wiki Tiki Wiki CMS Groupware. Esse wiki foi escolhido por possuir características importantes para os requisitos de controle de documentação como o controle fino de permissões, mecanismos de workflow e funcionalidades avançadas de categorização, controle de versões e de histórico. Além disso, ele apresenta amplo número de plug-ins, extensões e outros mecanismos que permitem uma customização avançada do funcionamento do sistema e das páginas wiki.

As principais funcionalidades utilizadas no WikiQMS na primeira versão desenvolvida consistiram no wiki propriamente dito, galeria de arquivos utilizada para gerenciar figuras, documentos externos e registros preenchidos, formulários utilizados para administrar a lista de distribuição dos documentos, grupos de permissões, categorias e transições, controle de versões e histórico, mecanismo de busca e lista de últimas mudanças realizadas nos documentos do WikiQMS.

$\mathrm{O}$ wiki propriamente dito consiste no gerenciador de páginas wiki que é utilizado para armazenar e manipular os documentos do Sistema de Gestão da Qualidade em formato de hipertexto. Um exemplo de documento da qualidade nesse formato está na Figura 3.

A galeria de arquivos, por sua vez, tem por função armazenar figuras utilizadas nos documentos do SGQ, documentos externos de formatos diversos, além de registros preenchidos. Ela tem as funções de um gerenciador de documentos eletrônicos, ou seja, permite a inclusão, designação de permissões, busca, atualização e remoção de arquivos.

Os formulários são utilizados internamente para gestão da lista de distribuição. A lista de distribuição foi concebida para que sejam definidos usuários específicos que recebem $e$-mail de notificação de novo documento publicado ou nova revisão e que devem confirmar ter consciência do novo documento publicado ou da nova revisão. A lista de distribuição se encontra após a demarcação do fim do documento, como ilustrado na Figura 4.

O WikiQMS contém quatro grupos de permissões aos quais os usuários podem ser associados. A alocação dos usuários em cada um dos grupos influi nas áreas de conteúdo que eles podem visualizar nas telas do sistema, nas permissões dentro das funcionalidades ativadas e também no seu papel dentro do workflow de aprovação dos documentos. Os grupos de permissões estão esquematizados na Figura 5.

O grupo de acesso deve incluir todos os usuários que podem visualizar apenas os documentos publicados. Já o grupo de edição herda as permissões do grupo de acesso e também pode criar, modificar e submeter à aprovação os rascunhos de documentos. O grupo

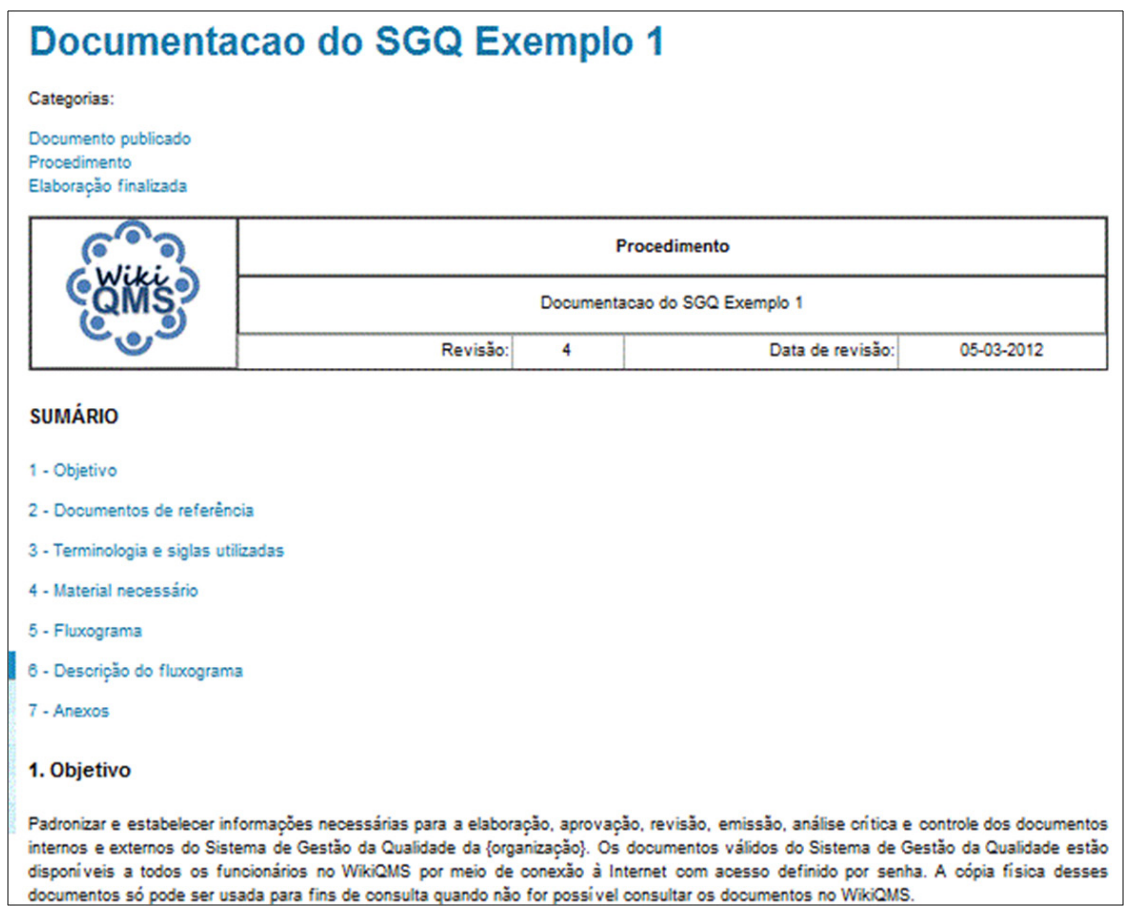

Figura 3. Exemplo de documento. Fonte: WikiQMS (2012). 


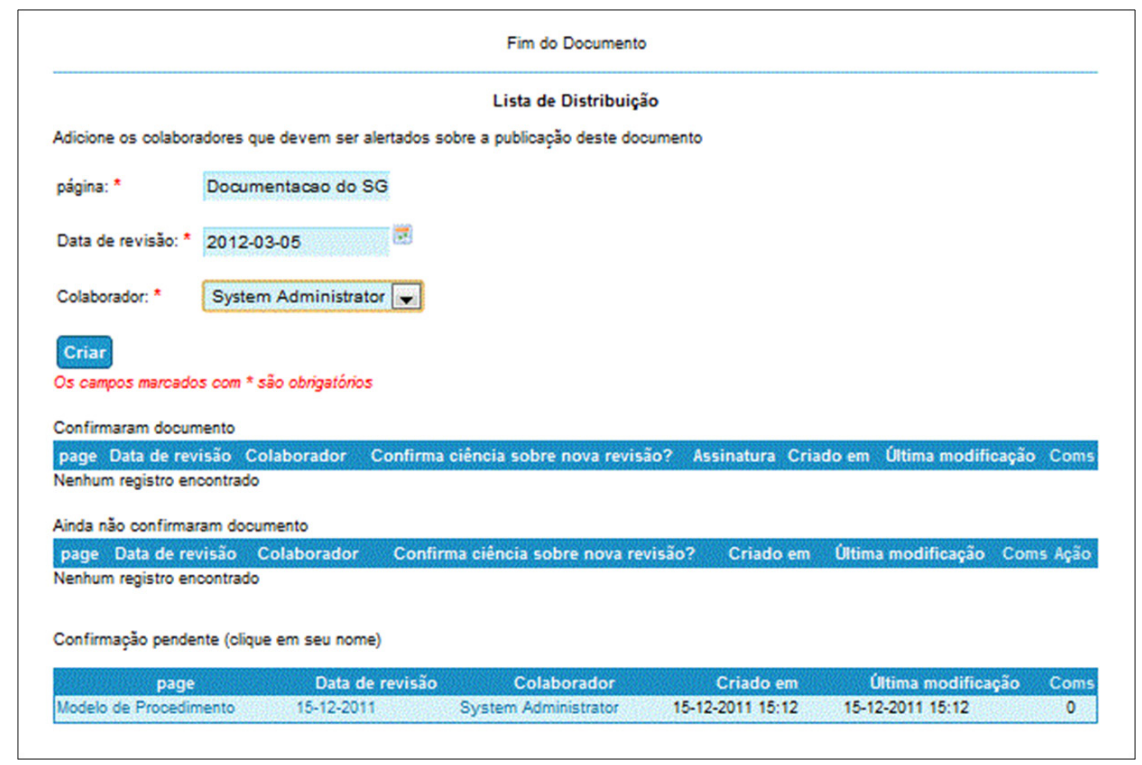

Figura 4. Lista de distribuição. Fonte: WikiQMS (2012).

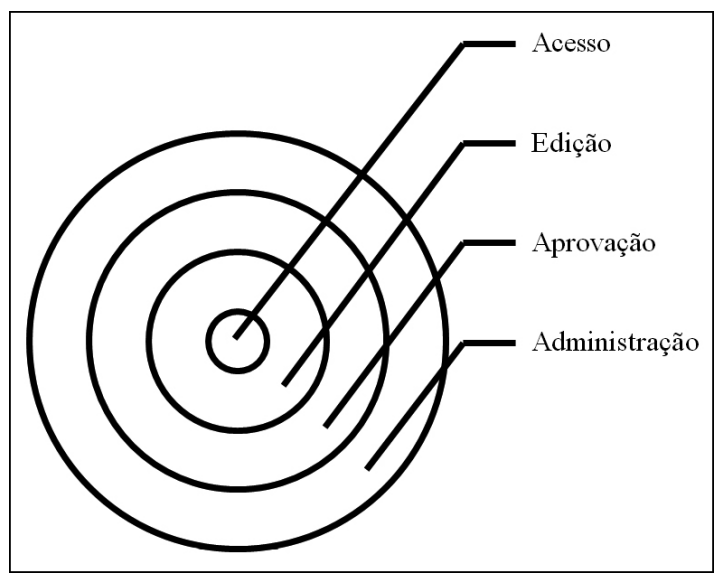

Figura 5. Grupos de permissões. Fonte: Autores.

de aprovação, além de possuir as permissões dos grupos de acesso e edição, também pode realizar a primeira etapa de aprovação do rascunho. Por fim, o grupo de administração herda as permissões dos demais e pode realizar a última etapa de aprovação do rascunho e a publicação.

O workflow de aprovação, uma das customizações mais importantes para o WikiQMS, foi construído a partir das categorias e transições, amparando-se também nos grupos de permissões. Essa funcionalidade se apoia na diferenciação entre o rascunho e o documento publicado, o qual é identificado pelo título (no título do rascunho, aparece um “*” antes do nome) e também na lista de categorias, que se encontra após o título do documento.

$\mathrm{O}$ workflow envolve a categorização do rascunho e a mudança da categoria a que ele pertence pelos usuários com permissão para realizar a transição de uma categoria para outra. A cada transição, um e-mail é enviado ao grupo responsável pela etapa seguinte para avisá-lo de que a próxima transição do rascunho se encontra sob sua responsabilidade. Esse fluxo normalmente finaliza com a publicação do documento, em que o conteúdo do rascunho é copiado e transferido para o documento publicado.

O controle de versões e histórico consiste em uma funcionalidade comum aos softwares wiki, sendo uma de suas características mais bem desenvolvidas. Ele permite a identificação das alterações efetuadas nos documentos por meio do armazenamento das versões do documento e também por meio de um mecanismo de comparação entre as versões. No histórico do documento, ficam registrados autor, data e descrição da modificação inserida pelo autor. A comparação do conteúdo das versões ressalta as diferenças entre elas com marcações como riscos, frases com cores diferentes, sinais de “+”, por exemplo.

As duas últimas funcionalidades - mecanismo de busca e lista de últimas mudanças - são transversais ao WikiQMS. Elas estão presentes no menu do sistema e podem ser acessadas facilmente a qualquer momento. O mecanismo de busca facilita a recuperação dos documentos ao permitir a busca de termos no título e no conteúdo dos documentos. Já a lista de últimas mudanças apresenta o título dos documentos que foram modificados na ordem do mais recente para a mais antiga, com um limite de itens a serem mostrados.

\subsubsection{Melhorias do protótipo em sua última versão}

A primeira versão do WikiQMS foi submetida à avaliação de especialistas. A avaliação em geral foi positiva e a análise de conteúdo das respostas dos 
especialistas ao questionário do painel ressaltou 31 questões que levaram a mudanças no protótipo. Dessas, nove foram implantadas na versão final do protótipo. As demais foram consideradas incompatíveis com a proposta do WikiQMS ou formaram uma lista de sugestões futuras de intervenção.

As principais mudanças feitas no protótipo para atender parcial ou totalmente às questões levantadas pelos especialistas foram um mecanismo para visualizar a relação entre os documentos, o calendário de eventos, o mecanismo de atribuição e controle de tarefas e a alteração do workflow.

Para apoiar a visualização de como um determinado documento se relaciona com os demais, foi ativado e configurado um mecanismo de visualização 3D da relação entre documentos em wiki por meio da exploração de links entre os documentos. Um exemplo de utilização dessa ferramenta está ilustrado na Figura 6.

Em resposta à crítica de falta de controle de prazos para a elaboração e aprovação dos documentos foram ativados também o calendário de eventos e o mecanismo de atribuição de tarefas entre usuários. O calendário de eventos permite a inclusão de eventos, os quais ficam visíveis no menu do WikiQMS. Já o mecanismo de atribuição de tarefas permite que um usuário atribua a si ou outro usuário ou grupo de usuários uma determinada tarefa, com sua descrição e com uma previsão de término. Ao longo da execução, o usuário pode atualizar a porcentagem de conclusão da tarefa.

O workflow apresentado inicialmente foi alterado em resposta a um alerta levantado por alguns especialistas sobre a questão da obsolescência de documentos. O workflow da versão final do WikiQMS está representado na Figura 7. Nele está contemplada a possibilidade de tornar um documento e seu rascunho obsoletos após a revisão do rascunho e também de retornar um rascunho que estava obsoleto à edição, permitindo sua alteração e republicação como documento oficial.

Além das alterações mencionadas, a configuração final das telas e permissões foi definida. A Figura 8 apresenta o esquema de telas e as permissões dos grupos para cada área de conteúdo dentro das telas do WikiQMS.

A tela "página inicial" contém links para as seções de cada tipo de documento do Sistema de Gestão da Qualidade (manual da qualidade, procedimentos, instruções de trabalho e registros) e também para a lista mestra. As seções de cada tipo de documento são padronizadas e possuem cinco áreas de conteúdo distintas: documentos publicados, área de criação de rascunhos, modelo de documento, lista dos rascunhos categorizados segundo o estado atual dentro do workflow de aprovação e a lista dos rascunhos e documentos obsoletos. Por fim, a tela "lista mestra" apresenta a lista dos documentos oficiais do SGQ, gerada automaticamente a partir dos documentos existentes no WikiQMS.

\subsubsection{Validação do protótipo}

O WikiQMS foi validado por meio da implantação na empresa Unifei Jr. Na preparação da implantação, quatro integrantes da organização participaram de

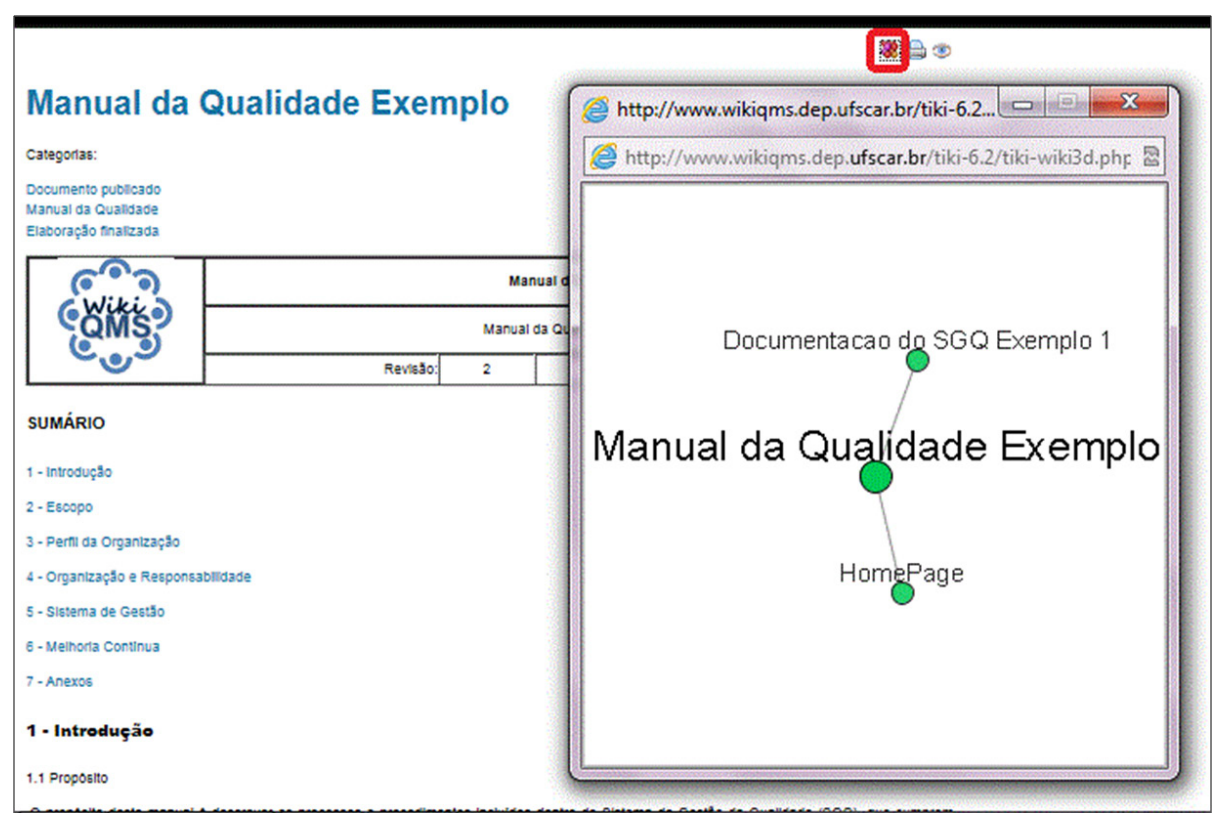

Figura 6. Visualização da relação entre documentos. Fonte: WikiQMS (2012). 


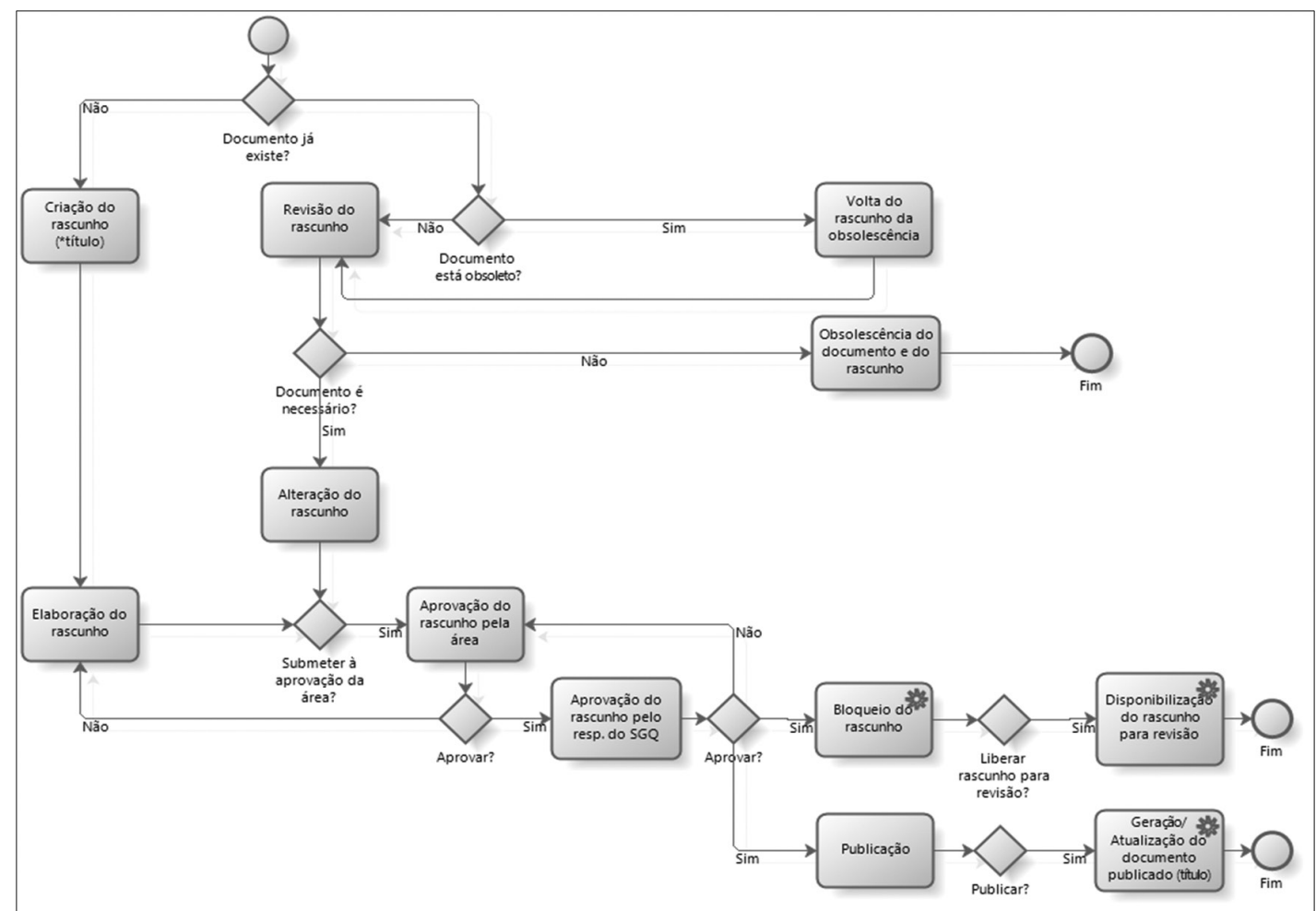

Figura 7. Workflow da versão final do WikiQMS. Fonte: Costal (2012, p. 107).

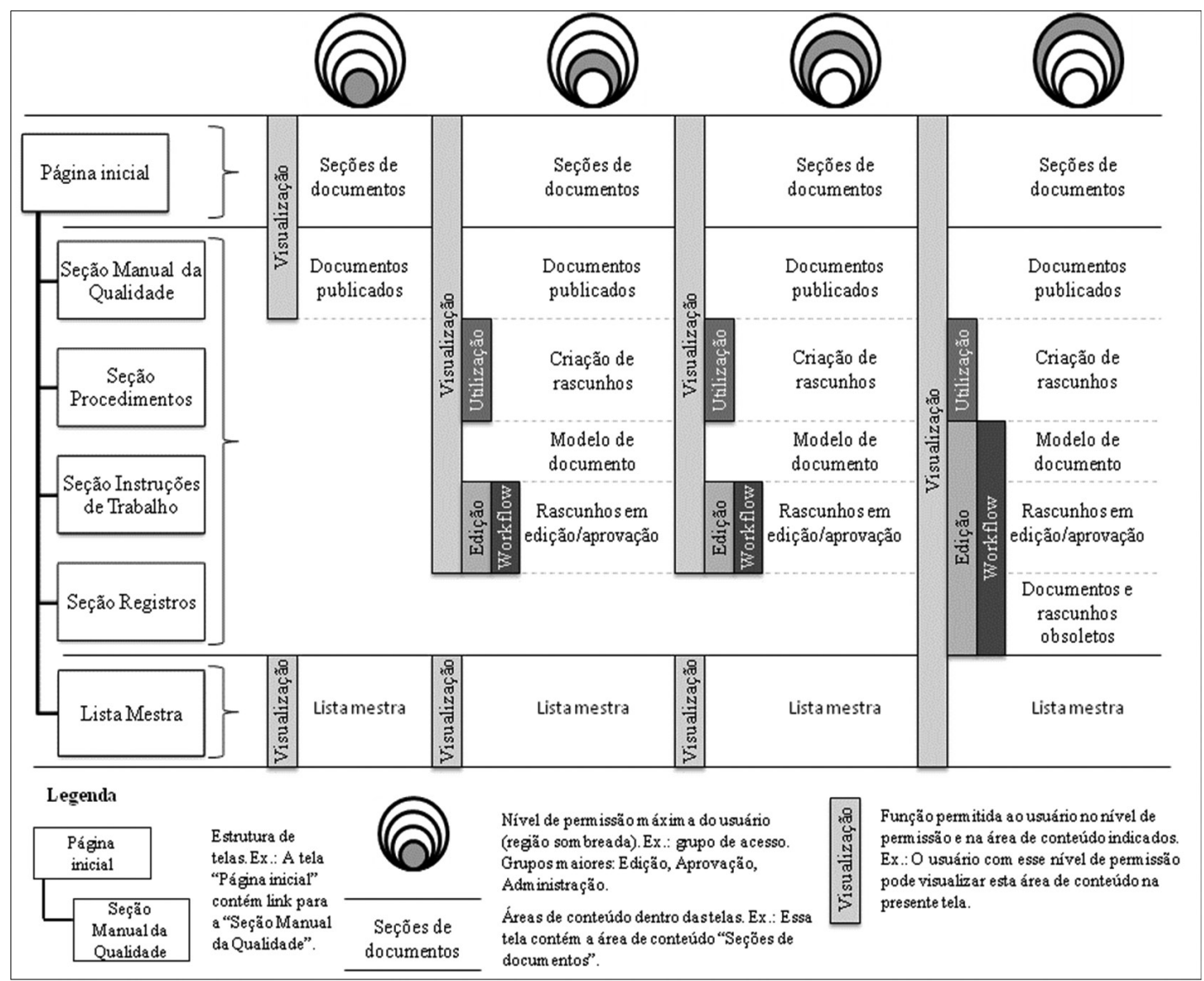

Figura 8. Esquema de telas do WikiQMS. Fonte: Costal (2012, p. 108). 
uma reunião em que foi apresentado o WikiQMS, seu funcionamento e como instalá-lo. A instalação do software Tiki Wiki CMS Groupware foi feita em um serviço de computação em nuvem para hospedagem de programas e sites, utilizando os manuais disponibilizados no site desse software. A configuração para implantação das características, telas e funcionalidades do WikiQMS foi feita a seguir.

Por fim, o WikiQMS foi utilizado pelos integrantes da equipe da Unifei Jr. para a implantação dos documentos de seu Sistema de Gestão da Qualidade. A organização, por não possuir ainda um SGQ, começou a implantação desde o início. No tempo designado para a validação foi feita a implantação completa de três procedimentos e a implantação incompleta de um procedimento e do manual da qualidade. As Figuras 9 e 10 mostram as seções do procedimento publicado PQ.02.01 - Controle de Registros.
Os principais resultados da validação foram o surgimento de questões ao longo das etapas que subsidiaram a elaboração da documentação do WikiQMS e a obtenção do feedback da equipe sobre o protótipo. Entre os documentos que receberam maiores contribuições, destaca-se o arquivo que orienta como deve ser feita a configuração do Tiki Wiki para a finalização da implantação do WikiQMS.

A avaliação da equipe foi positiva e as principais vantagens levantadas foram a atualização automática do número e da data de revisão dos documentos, a organização dos documentos com separação clara entre documentos publicados e rascunhos, a criação automática da lista mestra, a simplicidade e facilidade de acesso aos documentos, o controle de permissões e a facilidade de criarem-se links entre os documentos. Outro aspecto avaliado como positivo foi a possibilidade de comunicação por meio dos

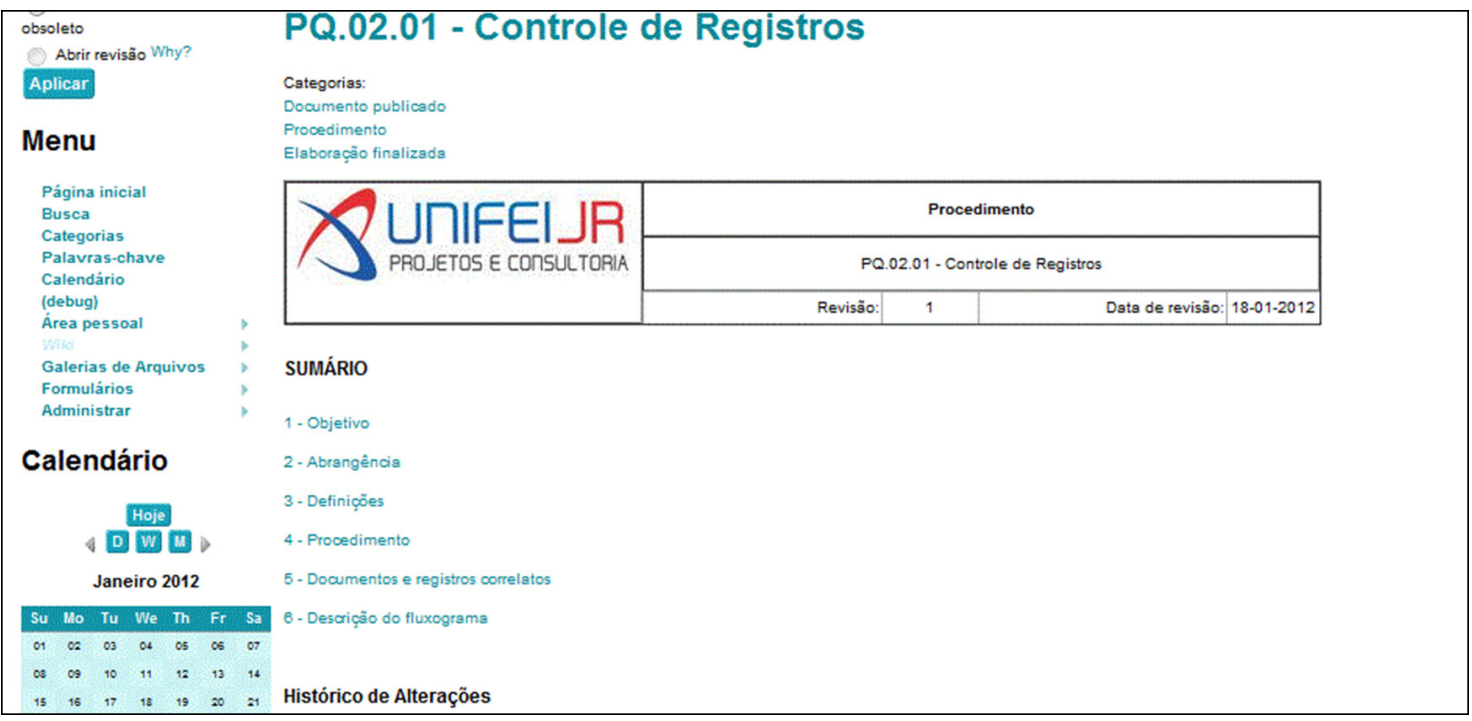

Figura 9. Seção inicial do procedimento PQ.02.01 - Controle de Registros. Fonte: Unifei Jr. (UNIVERSIDADE..., 2012).

\begin{tabular}{|c|c|}
\hline & 1. Objetivo \\
\hline \multicolumn{2}{|l|}{ Adacionar } \\
\hline & Definir diretrizes pars identificar, armazenar, proteger, recuperar, reter e descartar os registros da qualidade, de modo a demonstrar a operacionalidade \\
\hline pronto Dal & do sistema da qualidade. \\
\hline Últimas & 2. Abrangência \\
\hline \multicolumn{2}{|r|}{ Todas as áreas da empress. } \\
\hline 1. "PSQ 8.2.2 01 - Auditoria & \multirow{3}{*}{ 3. Definições } \\
\hline interns & \\
\hline 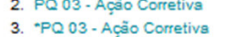 & \\
\hline 4. PQ.02.01-Controle de & 3.1. Registro: formulário que apresenta resultados obtidos ou fornece evidências de atividades realizadas. \\
\hline Registros & 3.2. Identificagäo do registro: nome e/ou código pelo qual o registro é $\infty$ nhecido dentro do sistema da qualidade. \\
\hline $\begin{array}{l}\text { 5. PQ.01- Elaboracao e } \\
\text { Controle de Documentos }\end{array}$ & \\
\hline $\begin{array}{l}\text { Controle de Documentos } \\
\text {...mais }\end{array}$ & $\begin{array}{l}\text { 3.3. Armazenamento do registro: forma ordenada e local adequado para arquivar e armazenar os registros de forma a evitar sua deterioração } \\
\text { e/ou danos. possibilitando a sus pronta recuperação. }\end{array}$ \\
\hline Busca & 3.4. Proteção do registro: cuidados necessários para evitar a perda ou a deterioração do registro. \\
\hline & 3.5. Recuperação do registro: forma utilizada para obtenção do registro quando da necessidade de demonstrar ou snalisar seus resultados. \\
\hline em: Todo o Site & $\begin{array}{l}\text { 3.6. Tempo de retenção do registro: tempo (dias, meses, anos) no qual o registro terá de ficar armazenado para fornecer as evidências objetivas } \\
\text { necesś́rias. }\end{array}$ \\
\hline Busces Titiog & - \\
\hline
\end{tabular}

Figura 10. Capítulos 1, 2 e 3 do procedimento PQ.02.01 - Controle de Registros. Fonte: Unifei Jr. (UNIVERSIDADE..., 2012). 
mecanismos de calendário e atribuição de tarefas. O único ponto negativo levantado foi a lentidão para a realização de alguns procedimentos, mas que não afetou o desempenho das tarefas.

Além dos pontos positivos e do ponto negativo, outra questão importante que surgiu na validação foram as limitações do WikiQMS. Dadas as características do Tiki Wiki e das adaptações realizadas, não se podem usar caracteres latinos no título dos documentos do SGQ e dos arquivos anexados à galeria de arquivos. Também deve-se evitar o procedimento de "colar" conteúdos de documentos de outras extensões diretamente na tela de edição do documento, sendo o procedimento correto utilizar as ferramentas disponíveis na barra de ferramentas do wiki para realizar essa transferência de conteúdo. Vale observar que esses problemas são comuns a outros softwares livres que ainda não dão suporte adequado às línguas latinas e também no caso do wiki, que é uma plataforma diferente em relação aos editores de texto comumente utilizados. No entanto, com a ampliação da utilização desses softwares no mundo, e particularmente no Brasil, e considerando as características das comunidades de desenvolvimento de software livre de rapidez na melhoria dos softwares e foco nas necessidades dos usuários, tal limitação tende a ser rapidamente resolvida. A URL http:// sourceforge.net/projects/wikiqms hospeda o projeto do WikiQMS, seus arquivos de configuração e documentação de suporte.

\section{Conclusões}

O WikiQMS é um sistema baseado em wiki para a gestão da documentação do Sistema de Gestão da Qualidade padrão ISO 9001. Ele foi desenvolvido com base na abordagem multimetodológica proposta por Nunamaker Junior, Chen e Purdin (1990), ilustrada na Figura 2. O desenvolvimento foi iniciado com o levantamento dos requisitos da norma ISO 9001 quanto à documentação e recomendações em relação à implantação e manutenção de um SGQ nas organizações. Esses requisitos foram definidos a partir da revisão da literatura e também da interação com o campo, por meio de um painel de especialistas e da validação em uma situação real. A informatização da documentação de SGQ não é uma solução nova para um problema antigo - a documentação de um SGQ padrão ISO 9001. Contudo, este artigo trouxe a proposta de fazê-la com uso de uma solução Web 2.0 para qualquer organização e sem custos de licença para uso do software bem como sem investimentos altos em hardware.

A utilização de software wiki também não é nova, mas trata-se de um campo de pesquisa novo, como pode ser observado no Quadro 2 - apenas quatro implantações foram encontradas na literatura pesquisada. Todavia, diferentemente das propostas encontradas na pesquisa bibliográfica realizada, o WikiQMS descrito neste artigo foi construído a partir de critérios gerais para informatização da documentação do SGQ, sem se limitar à aplicação em uma organização específica. Assim, ele poderá ser customizado de acordo com as características específicas de cada organização. Além disso, a proposta apresentada neste artigo foi desenvolvida a partir da aplicação do método científico e de uma base teórica bem definida. Isso não fica claro nas propostas encontradas na literatura e desenvolvidas para situações específicas. Diferentemente das outras propostas do Quadro 2, o WikiQMS não utiliza plug-ins que não aqueles já desenvolvidos para o próprio Tiki Wiki e nem outros softwares open source ou proprietários, como fazem as propostas de Castaño, Mendez e Day (2012) e de Lavrsen (2007). As funcionalidades e os plug-ins desenvolvidos pela comunidade do Tiki Wiki tornaram isso possível.

O WikiQMS foi avaliado positivamente tanto pelos especialistas quanto pelos integrantes da equipe de validação. As principais vantagens levantadas foram a facilidade de uso, a geração automática de informações da situação da revisão atual dos documentos e a facilidade de comunicação por meio das ferramentas disponíveis. Além disso, a característica que torna o WikiQMS mais atraente em relação aos softwares proprietários consiste no custo zero de aquisição e na inexistência da necessidade de adquirir licenças para sua utilização.

O desenvolvimento do WikiQMS explora novas possibilidades no campo de informatização da documentação do Sistema de Gestão da Qualidade, na medida em que o produto final não só atende aos requisitos de documentação da ISO 9001 como também facilita a implantação e melhoria do SGQ. Tal aspecto deriva do uso de um wiki, uma das principais tecnologias da Web 2.0, para a criação do sistema. Dessa forma, o software utiliza-se dos mecanismos do wiki para favorecer a colaboração na gestão da qualidade, mas também assegura que os requisitos de segurança, controle e acesso à documentação da ISO 9001 sejam atendidos.

O WikiQMS apresenta algumas limitações importantes como a necessidade de evitar o uso de caracteres latinos no título dos documentos e arquivos e também de evitar o procedimento de "colar" conteúdos de arquivos em outros formatos diretamente no corpo do documento em wiki. No entanto, essas limitações tendem a ser eliminadas com o desenvolvimento contínuo do Tiki Wiki pelas comunidades de desenvolvedores de softwares livres.

Como sugestão de trabalho futuro, destaca-se a necessidade de validar o sistema em outras organizações com características diferentes daquelas encontradas na Unifei Jr. - usuários jovens e receptivos à tecnologia Web 2.0. Vale destacar que 
as implantações de Castaño, Mendez e Day (2012), de García et al. (2010), de Gomide (2009) e de Lavrsen (2007) se deram em ambientes semelhantes. Dessa forma, fazem-se necessárias implantações em outros ambientes e com culturas diferentes de informática. Por fim, sugere-se também a adequação do WikiQMS para o atendimento dos demais requisitos da ISO 9001 e, também, dos requisitos de sistemas integrados de gestão, como OSHA 18001 e ISO 14001.

\section{Agradecimentos}

À FAPESP pelo apoio financeiro para realização da pesquisa (processo n²010/04697-8, Fundação de Amparo à Pesquisa do Estado de São Paulo - FAPESP), aos especialistas que participaram do painel e à diretoria e membros da Unifei Jr. que participaram da validação do WikiQMS.

\section{Referências}

ANHOLON, R.; ZOQUI, E. J.; PINTO, J. S. Principais dificuldades vivenciadas na implementação de um sistema de gestão da qualidade adaptado em empresas incubadas na região de Jundiaí. 2005. In: ENCONTRO NACIONAL DE ENGENHARIA DE PRODUÇÃO, 25., 2005, Porto Alegre. Anais... Porto Alegre: ABEPRO, 2005. Disponível em: $<$ http://www. abepro.org.br/biblioteca/ ENEGEP2005_Enegep 0201_0519.pdf>. Acesso em: 20 ago. 2010.

ANTUNES, F. L.; RIBEIRO, J. L. D. Acreditação hospitalar: um estudo de caso. Revista Produção Online, v. 5, n. 1, p. 1-27, 2005.

ASSOCIAÇÃO BRASILEIRA DE NORMAS TÉCNICAS - ABNT. NBR ISO 9000: sistemas de gestão da qualidade: fundamentos e vocabulário. Rio de Janeiro: ABNT, 2005.

ASSOCIAÇÃO BRASILEIRA DE NORMAS TÉCNICA̧S - ABNT. NBR ISO 9001/2008: sistemas de gestão da qualidade - requisitos. Rio de Janeiro: ABNT, 2008.

BEST, D. Web 2.0: next big thing or next big Internet bubble? Technische Universiteit Eindhoven, 2006. Disponível em: <http://paqe.mi.fu-berlin.de/ best/uni/ WIS/Web2.pdf $>$. Acesso em: $11 \mathrm{dez} .2009$.

CAMPOS, V. F. TQC: controle da qualidade total no estilo japonês. 5. ed. Belo Horizonte: UFMG, 1992. 229 p.

CAMPOS, V. F. Qualidade total: padronização de empresas. Nova Lima: INDG Tecnologia e Serviços, 2004. 142 p.

CARDOSO, J. C.; LUZ, A. R. Os arquivos e os sistemas de gestão da qualidade. Arquivo \& Administração, v. 3, n. 1-2, p. 51-64, 2004.

CARPINETTI, L. C. R.; MIGUEL, P. A. C.; GEROLAMO, M. C. Gestão da qualidade ISO 9001:2008: princípios e requisitos. São Paulo: Atlas, 2010. 111 p.

CASADESÚS, M.; HERAS, I.; ARANA, G. Costes y beneficios de la implantación de la normativa de calidad ISO 9000: evolución temporal. In: CONGRESO NACIONAL ACEDE, 14., 2004, Murcia. Proceedings... Murcia: ACEDE, 2004. p. 45-51.
CASTAÑO, F.; MENDEZ, G.; DAY, L. Geometrica Builds ISO 9001 QMS on Wiki. American Society for Quality (ASQ), 2012. Disponível em: <http://asq.org/ knowledge-center/iso-9001-qms-wiki.html>. Acesso em: 30 abr. 2013.

CIANFRANI, C. A.; TSIAKALS, J. J.; WEST, J. E. J. ISO 9001:2008 explained. 3. ed. Milwaukee: ASQ Quality Press, 2009. 295 p.

COSTAL, G. C. S. Z. Adaptação do software wiki para informatização da documentação do sistema de gestão da qualidade padrão ISO 9001. 2012. $171 \mathrm{f}$. Dissertação (Mestrado em Engenharia de Produção)Centro de Ciências Exatas e de Tecnologia, Universidade Federal de São Carlos, São Carlos, 2012.

COSTAL, G. C. S. Z.; MARTINS, R. A. Análise das vantagens da utilização de software wiki para informatização da documentação do sistema de gestão da qualidade ISO 9001. In: ENCONTRO NACIONAL DE ENGENHARIA DE PRODUÇÃO, 30., 2010, São Carlos. Anais... São Carlos: ABEPRO, 2010. Disponível em: <http://www.abepro.org.br/biblioteca/ enegep2010_TN_STO_114_748_16854.pdf>. Acesso em: 11 jun. 2011.

COSTAL, G. C. S. Z.; MARTINS, R. A. Dificuldades na informatização de um sistema de gestão da qualidade baseado na norma ABNT ISO 9001. In: ENCONTRO NACIONAL DE ENGENHARIA DE PRODUÇÃO, 31., 2011, Belo Horizonte. Anais... Belo Horizonte: ABEPRO, 2011. Disponível em: <http://www. abepro.org.br/biblioteca/enegep2011_TN_STO_136_864 _18128.pdf>. Acesso em: 01 nov. 2011.

DEPEXE, M. D.; PALADINI, E. P. Dificuldades relacionadas à implementação e certificação de sistemas de gestão da qualidade em empresas construtoras. Revista Gestão Industrial, v. 3, n. 1, p. 13-25, 2007. http://dx.doi. org/10.3895/S1808-04482007000100002

DOUGLAS, A.; COLEMAN, S.; ODDY, R. The case for ISO 9000. TQM Magazine, v. 15, n. 5, p. 316-324, 2003. http://dx.doi.org/10.1108/09544780310487712

EBERSBACH, A. et al. Wiki: Web collaboration. 2. ed. Berlin Heidelberg: Springer-Verlag, 2008.

ELSMAR COVE QUALITY ASSURANCE AND BUSINESS STANDARDS WIKI. Using a wiki for QMS documentation. Elsmar Cove, 2009. Disponível em: <http://elsmar. com/wiki/index.php/Using_a_wiki_ for_QMS_documentation>. Acesso em: 02 jun. 2010.

FEIGENBAUM, A. V. Controle da qualidade total. São Paulo: Makron, 1994. v. 1.

GALLIERS, R. D.; LAND, F. F. Choosing appropriate information systems research methodologies. Communications of the ACM, v. 30, n. 11, p. 900-902, 1987. http://dx.doi.org/10.1145/32206.315753

GARCÍA, R. et al. A Semantic Wiki for Quality Management in Software Development Projects. IET Software, v. 4, n. 6, p. 1-19, 2010. http://dx.doi.org/10.1049/ iet-sen.2010.0044

GOMIDE, A. B. MediaWiki: Proposta de uma configuração do software visando atender os requisitos da norma ISO 9001:2008. In: ENCONTRO NACIONAL DE ENGENHARIA DE PRODUÇÃO, 29., 2009, Salvador. Anais... Salvador: ABEPRO, 2009. Disponível em: 
$<$ http://www.abepro.org.br/biblioteca/enegep2009_TI_ ST_098_662_12886.pdf>. Acesso em: 16 maio 2010.

HALL, W. The ever evolving Web?: the power of networks. Journal of Communication, v. 5, p. 651-664, 2011.

HOYLE, D. ISO 9000: quality systems handbook. Oxford: Elsevier, 2009. 802 p.

INTERNATIONAL ORGANIZATION FOR STANDARDIZATION (ISO). The ISO survey. Genebra: ISO, 2013. Disponível em: <http://www.iso.org/iso/ home/standards/certification/iso-survey.htm > . Acesso em: 30 set. 2013.

LAVRSEN, K. Motorola Tetra World Wide System Development (TWSD). 2007. Disponível em: <http://twiki.org/cgi-bin/view/Main/ TWikiSuccessStoryOfMotorola>. Acesso em: 03 maio 2010.

LEUF, B.; CUNNINGHAM, W. The wiki way: quick collaboration on the web. Boston: Addison-Wesley Professional, 2001.

McAFEE, A. Enterprise 2.0: new collaborative tools for your organization's toughest challenges. Boston: Harvard Business Press, 2009. 231 p.

MELLO, C. H. P. et al. ISO 9001:2008: sistema de gestão da qualidade para operações de produção e serviços. São Paulo: Atlas, 2009. 239 p.

MILLER, P. Web 2.0: Building the new library. Ariadne, n. 45, 2005. Disponível em: <http://www.ariadne.ac.uk/ issue 45/miller/ >. Acesso em: 14 jun. 2010.

NEWMAN, A. C.; THOMAS, J. G. Enterprise 2.0 implementation. New York: McGraw-Hill, 2009. 406 p.

NILLES, M. B. A hard look at quality management software. Quality Digest, 2001. Disponível em: <http://www. qualitydigest.com/oct01/html/qmsw.html>. Acesso em: 08 mai. 2010.

NUNAMAKER JUNIOR, J. F.; CHEN, M.; PURDIN, T. D. M. Systems development in information systems research. Journal of Management Information Systems, v. 7, n. 3, p. 89-106, 1990.

O'REILLY, T. What is Web 2.0?: Design patterns and business models for the next generation of software. O'Reilly, 30 set. 2005. Disponível em: <http://www. oreillynet.com/lpt/a/6228>. Acesso em: 24 mai. 2010.

PINTO, S. H. B.; CARVALHO, M. M. D.; HO, L. L. Implementação de programas de qualidade: um survey em empresas de grande porte no Brasil. Gestão Produção, v. 13, n. 2, p. 191-203, 2006. http://dx.doi.org/10.1590/ S0104-530X2006000200003

POKSINSKA, B.; EKLUND, J. A. E.; DAHLGAARD, J. J. ISO 9001:2000 in small organisations: lost opportunities, benefits and influencing factors. International Journal of Quality \& Reliability Management. v. 23, n. 5, p. 490-512, 2006. http:// dx.doi.org/10.1108/02656710610664578

SAMPAIO, P.; SARAIVA, P.; RODRIGUES, A. G. ISO 9001 certification research: questions, answers and approaches. International Journal of Quality \& Reliability Management, v. 26, n. 1, p. 38-58, 2009. http://dx.doi. org/10.1108/02656710910924161

SILVA, E. DOC-SGQ: informatização da documentação do sistema de gestão da qualidade (SGQ). Cornélio Procópio: UTFPR/Campus Cornélio Procópio, 2006. 128 p. Trabalho de Diplomação. Disponível em: <http://pessoal. utfpr.edu.br/fabricio/ensino/orientacoes/ monografiaevertonsilva.pdf>. Acesso em: 20 mai. 2010.

SLONGO, G. et al. Implementação de um sistema de gestão da qualidade conforme a norma ISO 9001: 2000 numa pequena empresa de base tecnológica, estudo de caso: Solar Instrumentação, Monitoração e Controle Ltda. In: Encontro Nacional de Engenharia de Produção, 25., 2005, Porto Alegre. Anais... Porto Alegre: ABEPRO, 2005. Disponível em: <http://www.peteps.ufsc.br/novo/ attachments/083_083_artigo_solar_ISO_enegep2005. pdf>. Acesso em: 11 ago. 2010.

STEVENSON, T. H.; BARNES, F. C. Fourteen years of ISO 9000: impact, criticisms, costs, and benefits. Business Horizons, v. 44, n. 3, p. 45-51, 2001. http:// dx.doi.org/10.1016/S0007-6813(01)80034-3

SPRAGUE, R. Eletronic document management: challenges and opportinities for information systems managers. MIS Quarterly, v. 19, n. 1, 1995. Disponível em: <http:// www.shidler.hawaii.edu/sprague/MISQ/MISQfinal. htm>. Acesso em: 18 out. 2011.

TREDINNICK, L. Web 2.0 and business: a pointer to the intranets of the future? Business Information Review, v. 23, n. 4, p. 228-234, 2006. http://dx.doi. org/10.1177/0266382106072239

UNIVERSIDADE FEDERAL DE ITAJUBÁ - UNIFEI JR. WIKIQMS - Unifei Junior. Disponível em: <http:// www.unifeijr.com.br/wiki/>. Acesso em: 19 jan. 2012.

VASQUES, A. O. Desenvolvimento de um sistema web de controle de documentos baseado nas normas de qualidade ISO 9001:2000. 2007. 96 f. Trabalho de Conclusão de Curso (Graduação)-Centro Universitário Feevale, Instituto de Ciências Exatas e Tecnológicas, Novo Hamburgo, 2007.

WIKIQMS. Disponível em: <http://www.wikiqms.dep. ufscar. br>. Acesso em: 19 jan. 2012. 